\title{
George Santayana ve Epifenomenal Natüralizmin Olanaklılığı
}

Aysun Aydın ${ }^{1}$

\section{ÖZET}

Amerikan Pragmatist Natüralist Felsefe Geleneğinin en önemli temsilcilerinden biri olan George Santayana, hem bu geleneğin temel kavramlarını sürdürmek bakımından hem de kendine özgü ve farklı bir metafizik kavramsallaştırma sunmak bakımından farklı bir yere sahiptir. Felsefesini natüralizm temelinde tanımlayan George Santayana, natüralist geleneğin klasik materyalist çizgisinden tin, öz, töz gibi idealist düşünsel kavramları kabul edip tanımladığı için ayrılır. Bununla beraber, bu kavramsal çerçevesini epifenomenal materyalist görüş ile bağdaştıran Santayana, bu nedenle natüralist geleneğin klasik materyalist anlayışını benimseyen düşünürler tarafından eleştirilir. Santayana, bu düşünsel kavramlara dayanan natüralist bakış açısını gerçek natüralizm olarak tanımlayarak, felsefenin konusunu bu düşünsel kavramların doğal kökenlerinin araştırılması olarak tanımlar. Bu bağlamda, bu çalışmanın amacı, Santayana'nın natüralist kavramsallaştırmasını sunmak ve kendisine yapılan eleştiriler bağlamında düşünürün idealist ve epifenomenal natüralizminin natüralist felsefe geleneği içindeki yerini değerlendirmek ve analiz etmektir.

Anahtar Kelimeler: George Santayana, doğa, natüralizm, idealizm, epifenomenalizm.

\section{George Santayana and the Possibility of Epiphenomenal Naturalism}

\begin{abstract}
George Santayana, who is one of the important representers of American Pragmatic Naturalist Philosophical tradition, has a different role with respect to both retaining the main conceptions of this tradition and presenting a different and distinctive metaphysical conception. Santayana defines his philosophy on the basis of naturalism but he falls away from classical materialism of naturalist tradition because he accepts and defines idealist spiritual concepts; such as spirit, essence and substance. On the other hand, he associates his conceptual framework with the view of epiphenomenal materialism and for this reason he is criticized by classical materialist accounts of naturalism. Santayana defines his naturalistic view, that is based on these spiritual concepts, as genuine naturalism and he presents the subject of philosophy as the investigation of natural origins of these spiritual concepts. In this context, the aim of this study is to present the naturalistic conception of Santayana and to evaluate and analyze the place of his his idealist naturalism in philosophy, within the framework of criticisms to his position.
\end{abstract}

Keywords: George Santayana, nature, naturalism, idealism, epiphenomenalism.

\section{GíRiş}

Amerikan Pragmatizm ve Natüralizm geleneğinin önemli temsilcilerinden biri olan George Santayana (1863-1952), kendisinden önce gelen Amerikalı düşünürlerden, özellikle de William James ve Josiah Royce'dan etkilenmiş ve pragmatizmin bir diğer önemli temsilcisi olan John Dewey ile aynı dönemde yaşamıştır. Diğer pragmatist düşünürlerden farklı olarak, Santayana da Dewey gibi Pragmatik Natüralizm ekolünü benimsemiş ve eserlerinde yeni bir natüralizm tanımlamaya çalışmıştır. Dewey ile natüralizm konusunda birbirlerini eleştirdikleri yazışmalarında kendi natüralist yaklaşımını "gerçek

${ }^{1}$ Dr. Öğretim Üyesi, Düzce Üniversitesi, Felsefe Bölümü, aysunaydin@duzce.edu.tr 
natüralizm" (1925) olarak tanımlayan Santayana, Kuşkuculuk ve Hayvan İnancı (1923 - Scepticism and Animal Faith) adlı eserinde geleneksel deneycilik eleştirisini ve kendi natüralist yaklaşımını sunmaktadır. Santayana'nın felsefesi erken dönemlerinde içerdiği Platoncu öğeler ve özcü yaklaşımı nedeniyle materyalist natüralist düşünürler tarafından eleştirilerek 'idealist natüralizm' olarak tanımlanırken, çağdaş Santayana yorumcuları Santayana'nın natüralizminin materyalist öğelerini öne çıkararak ve düşünürün epifenomenal materyalizmini açıklayarak düşünürü savunmaktadırlar.

Santayana'nın felsefesini ve metafizik sistemini tek bir felsefi ekolün çatısı altında tanımlamak olanaklı değildir. Bunun bir nedeni düşünürün geleneksel felsefe içinde etkilendiği düşünürlerin çeşitliliği ve diğer bir nedeni de düşünürün farklı anlamlar yükleyerek geleneksel felsefenin bazı temel kavramlarını yeniden tanımladığı kavramsal çerçevesidir. Santayana bir felsefi sistem sunmaya çalışmamıştır. Felsefi eserlerinin yanı sıra şiir kitapları ve romanları da bulunan düşünür, eserlerinde bir yandan Platon ve Nietzsche etkisini göstermiş, diğer yandan çağının metafizik sorularına Pragmatik Natüralizm perspektifinden yanıt aramaya çalışmıştır. Platonculuk ve Manevi Yaşam (1927 - Platonism and The Spiritual Life) adlı eserinde Platonun temel kavramlarını yeniden sunan düşünürün felsefesi, çağının düşünürleri tarafından Platoncu kavramsal çerçeve ile natüralizmi uzlaştırma çabası olarak yorumlanmıştır. $\mathrm{Bu}$ farklılıkları nedeniyle, Amerikan felsefesinde pragmatist düşünürler arasında ayrıcalıklı bir yere sahip olan Santayana, ölümünden sonra da felsefesi üzerine farklı bakış açıları bulunan ve yeniden yorumlanan düşünürler arasındadır.

Santayana'nın felsefesinin tek bir felsefi düşünce tarafindan temsil edilemeyeceğini belirten T. M. Munson (1962), düşünürün felsefesini "gözlem felsefesi" olarak tanımlar ve Santayana'nın felsefesinin karakterinin onun ne olmadığını söylemek olduğunu söyler. Buna göre "Santayana'nın felsefesi (1) bir varoluşsal öznelcilik (existential subjectivity), (2) bir idealist sübjektivizm (idealistic subjectivism), ya da (3) geleneksel bir inançtan ilham almış bir sistem değildir" (s. 22). Öte yandan geç dönem eserlerinde Santayana kendisini natüralist olarak tanımlar ve felsefesini felsefi düalizm ve sübjektivizm ile baş edebilecek tek yol olan "gerçek natüralizm” olarak adlandırır. Bu açıdan, Santayana'nın natüralist yaklaşımını ve temel kavramlarını değerlendirmek, Amerikan natüralist geleneği değerlendirmek açısından önemlidir. Bu bağlamda, bu çalışmanın amacı; öncelikle Santayana'nın metafizik sistemini oluşturan öz, doğa, töz ve tin gibi epifenomenal nosyonları tanımlamak ve maddi dünya ile ilişkileri çerçevesinde ele almaktır. Daha sonra bu kavramlar çerçevesinde düşünürün natüralist yaklaşımının temel kabullerini açıklamak ve düşünürün iddia ettiği türden epifenomenal materyalizme dayanan bir natüralist kavramsallaştırmanın olanaklılığını sorgulayıp değerlendirmektir.

\section{Santayana Metafiziğinin Temel Kavramları}

Santayana'nın ontolojik kavramsallaştırması, insanın bu dünyada doğal şeyler arasında doğal bir organizma olarak bulunuşu ve bu organizmanın doğal dünya ile karşılaşması üzerine kuruludur. Santayana deneyci natüralizmin temel prensibi olarak deneyimi bilginin temeline koyar ve deneyimle doğayı özdeşleştirerek tüm varlığı doğal olarak kabul eder. Doğal ve doğal olmayan arasındaki ayrımı kaldıran Santayana, "hayvani inanç" tanımı ile insanı, doğada yaşamını sürdüren bir organizma yani biyolojik bir varlık olarak ele alır. Bu nedenle hayvana ait olan bu deneyim varlığın temelini oluşturur. Ancak Santayana bu deneyimi ve insanın varlık ile ilişkisini klasik deneyci ve doğalcı yaklaşımlardan farklı bir şekilde sunar. Kuşkuculuk ve Hayvan Inancı (1923) adlı eserinde "varlık dolayımsız bir zeminde bulunmaz, daima kuşkuya açıktır" (s. 39) diyen Santayana, klasik deneyci kabullerden farklı olarak insanın dış dünya ile ilişkisini dolayımsızlık prensibi üzerinden değil, dolayımsız olamayacağı kabulü üzerinden kurar ve insanın dünya ile ilişkisinin sınırlarını analiz eder. Buna göre varlık bir dolayımsızlık içinde verili değildir ve varlığı kavrayabilmenin tek koşulu Santayana'nın "hayvan aklı" olarak tanımladığı aklın özleri (essence) fark etmesi sürecidir. Buna göre varlık ve hayvan arasındaki ilişki özlerin varlığının hayvan aklı tarafından kavranmasına bağlıdır. Santayana için sadece bu hayvani akıl ve özlere dair bu kavrayış dış dünyaya karşı kuşkucu tutumları aşabilir.

Dolayısıyla Santayana, hayvan aklının varlık ile karşılaşmasında varlığa ait olan özler kabul eder. Santayana'nın özler dünyası ve madde dünyası şeklindeki iki dünya ayrımı da bu kabule dayanır. Santayana'nın öz tanımı Platon'un form kavramı ile ve maddeler dünyası ve özler dünyası arasında yaptığı ayrım Platon’un İdealar Kuramının iki dünya ayrımı ile ilişkilendirilse de, Santayana'nın öz kavramı epifenomenal bir nosyon olarak Platon'un formundan ayrılır. Bu noktada, Santayana'nın sözü edilen epifenomenal nosyonlarından ilki özdür. Santayana için özler dünyası sonsuz olanak taşıyan bir 
dünyadır ve özler sonsuz nesneler olarak basit ya da karmaşık yapıda olabilirler. Özler, hayvan ve doğa ya da dişsal nesneler arasındaki ilişkinin zeminini sağlarlar. Özler şeylerden ayrılamaz ya da soyutlanamazlar, onlar şeyler açıkça algılanmadan önce verilidirler ancak bu verili olma eylemde kör bir şekilde konumlanmıştır. Özler algıyla yani nesne üzerindeki ilgiye bağlı olarak ortaya çıkarlar ve nesne tarafindan akla ve aklın sembolleştirmesine sunulurlar (Santayana, 1923, s. 94). Santayana öz kavramını ona hafızada verdiği rolle açıklar. Düşünüre göre, özler şu an da aktif olmayan geçmişteki durumları yeniden yakalamamızı ya da kazanmamızı sağlar. Geçmişteki bir durumun özünü kavrayabiliriz ancak tözünü ya da varlık sinyalini kavrayamayız (Cory, 1950, s. 114).

Santayana hayvan ve dış dünya arasındaki ilişkiyi "hayvan inancı" (animal faith) kavramıyla açıklar ve özler bu ilişkide ortaya çıkar. Hayvani akıl bedenini ve dişardaki nesneleri keşfeder ve bu keşif sırasında özler dışsal nesnenin sembolü olarak ortaya çıkarlar. Birer sembol olarak özler, hayvana nesnenin bilgisini ve anlamını verirler. "Özler, doğadan çıkarak gelişen özgür sembollerdir" (Santayana, 1923, s. 95-98). Öte yandan Santayana, hayvan inancı, nesne ve öz arasındaki ilişkiyi ve bu ilişkinin koşullarını "söylem" (discourse) ya da "akli düşünme" (mind thinking) kavramları ile karşılar. Söylem, nesnenin değişimini, evrelerini, sürecini ve gerçeklikteki çeşitliliği kabul etmemizi sağlar (Santayana, 1923, s. 124). Söylem, hayvani aklın doğadan gelen özleri birer sembol olarak kavrayışıdır. Santayana söylemi "zorunlu olmayan bir başlangıç noktasında ve zorunlu olmayan bir ilerleme yönünde, özün taraflı, kişisel, tekrar eden ve zorunlu olmayan araştırması" (Santayana, 1923, s.134) olarak tanımlar. Söylem her şeyiyle, sadece varlığıyla değil sürekliliği, yönü ve kapsamı ile de, bir bütün olarak rastlantısaldır.

Söylem, hayvanın öz-benlik olarak ve bağımsız bir varlık olarak kendi varlığını keşfedişi ile deneyime dönüşür. Santayana bu kendi ile karşılaşmayı bir şok (shock) olarak tanımlar. Şok, hayvanın kendi özbenliğini, diğerlerinin birer benlik oluşunu ve kendisini etkileyen doğayı fark etmesidir. Şok hayvanın kendi varlığına olan inancının kaba deneyimidir. Deneyim hayvanın çevresindeki dünyayı keşfidir, varlığın özlerini ortaya çıkarmayı sağlar ve onlara bir düzen verir. Bu nedenle Santayana kendisini şöyle tanımlar; "Ben bir şair değil koleksiyoncuyum; beni ilgilendiren özleri keşfetmek değil, deneyim toplamaktır" (Santayana, 1923, s. 138).

Bu bağlamda, Santayana'nın hayvani aklın dış dünya ile ilişkisini hem dış dünyaya dair bir kavrayış hem de özne olarak kendi varlığına dair bir kavrayış şeklinde sunduğu görülmektedir. Deneyim, dış dünya ile karşılaşmada özlerin doğanın sembolleri olarak fark edilmesi ve özlerin deneyim nesnesi olarak kavranması gibi ikili bir süreç olarak ortaya çıkar. Bu açıdan, sembollerin kavranması olarak söylem ve söylem ile birlikte öz-benliğin kavranması deneyimi önceleyen süreçler ya da deneyimin koşullarıdır. Kuşkusuz Santayana, bu deneyim kavramsallaştırmasını ardışık evreler biçiminde sunmaz. Ancak deneyimin özlere dair bir fark ediş ve kavrayış süreci olarak açıklanması, Santayana'nın klasik natüralizmin dolayımsızlık prensibine karşı çıkışını açıklamaktadır.

Deneyci natüralizmin dolayımsızlık prensibine göre, deneyim insanın dış dünya ile karşılaşmasında nesnenin aracısız ve dolayımsız olarak, algıya konu olduğu haliyle kavranmasıdır (immediate experience). Bu prensip deneyimi önceleyen ve nesnenin maddi niteliklerini aşan bir kavrayışı kabul etmez. Bu açıdan baktığımızda, Santayana'nın öz kabulü ve özlerin nesnenin maddi niteliklerinden ayrı birer varlık olarak ve semboller olarak kavranışı bu prensip ile çelişir. Bu nedenle, Santayana dolayımsızlık prensibini reddeder ve deneyim ve doğa arasındaki ilişkiyi dolaylı olarak tanımlar. Santayana için deneyim doğayı dolayımsız olarak kavrayamaz, çünkü dolayımsız deneyim özlerin gerçek doğasını yakalayamaz. Santayana için deneyim, özlerin sezilmesi sürecinin sonucudur. Dolayımsızlık prensibini savunan düşünürler deneyimin bir içsel zihin durumu olmadığını ve doğayı doğrudan kavrayabileceğini iddia ederken, Santayana dolayımsızlığı deneyimi doğal nesnelere indirgemek olarak görür (Shook, 2003, s. 4).

Santayana'nın epifenomenal nosyonlarından ikincisi tözdür (substance). Madde Dünyası (1930 Realm of Matter) adlı eserinde töz kabulünü sunan Santayana, tözü "duyum için olanaklar" olarak tanımlar ve bu olanakların maddi bir şey olarak duyu deneyiminden bağımsız bir şekilde var olduğunu söyler. Santayana için töz, değişimden çok kalıcı olmayı, mekandan mekana ve biçimden biçime geçişe rağmen sürekliliğini koruyan şeyi temsil eder. Ancak bu töz kabulü, akışın tersi değil, akışın koşuludur. Bu nedenle töz, bir şeyin nedensel kalıcılığını değil, şeylerin akışı ile iç içe geçmiş bir varlığı temsil eder (akt. Cory, 1950, s. 117). Santayana için "töz inancı" insanın eylemlerinin zorunlu koşuludur. "Deneyim özlerin sezgisinden önce töz inancını (alarm gibi); tanımından önce isteğini getirir" (Santayana, 1923, s. 188). Bu nedenle Santayana töz kavramını insan aklına ait olan ve eylemlerin 
daimi arka planı olarak sunar. $\mathrm{Bu}$ açıdan, töz deneyimin hazır bir nesnesi değildir ve deneyim tarafından oluşturulmaz, ancak hayvan aklının eylemdeki inancı ya da varsayımıdır. Töz dış dünyanın varlığının ötesinde bir şey olarak hayvan aklında belirir. Bu noktada Santayana'nın özü deneyimin doğal bir arka planı olarak sunarken, tözü deneyimin doğaüstü ya da deneyimi önceleyen doğal olmayan bir arka plan olarak sunduğunu görmekteyiz. Özler maddi nesnenin sembolleri olarak doğal kabul edilirken, tözün doğal olduğu söylenememektedir. Santayana tözün varlığını, maddi zeminde bilinemez ama hayvan aklının zorunlu olarak varsaydığı bir inanç olarak sunar. Santayana'nın bu şekilde sunduğu töz kabulü de, geleneksel natüralizmin materyalist prensipleri ile çelişir ve bu türden bir töz kabulü nedeniyle Santayana idealist olmakla eleştirilir.

Tin (spirit) Santayana felsefesinde bir diğer önemli epifenomenal nosyondur. Tini de töz gibi maddi temelli bir şey olarak tanımlayan düşünür, tini insanın ahlaki ve estetik yaşantısının ve mutluluğunun koşulu olarak tanımlar. Tin gözlemlenebilen ya da herhangi maddi bir şey gibi karşılaşılabilen bir şey değildir. Tini insanın hakiki varlığından ayırıp başka bir dünya olarak tanımlayan düşünür, tinin kendini gerçekleştirebilmek için töze ve doğaya ihtiyacı olduğunu iddia eder ve tini şu şekilde tanımlar; "tin özler, zaman, mekan, değer arasındaki ayrımları ve çeşitliliği aydınlatan ve gösteren saf varlıktır ve doğanın yaratıcılığında doğada önceden var olan özleri yeni bir varlık dünyası olarak biçimlendiren varlıktır" (Santayana, 1923, s. 274). Tinin ruhla özdeşleşen ve doğadan ya da bedenden başka bir dünyadaki varlığı, Santayana felsefesinde düalizm problemini ortaya çıkarmaktadır, ancak düşünür tinin maddi oluşu konusunda 1srar etmektedir. Bu noktada yine Santayana'nın epifenomenalist bakış açısı karşımıza çıkar. D. Cory (1950), Santayana felsefesinde tinin varlığını ve beden ile ilişkisini, zihin-beden probleminde sıklıkla karşımıza çıkan bir tür epifenomenalizm olarak yorumlar. Epifenomenalist açıklamaya göre, ruh ya da zihin ile beden arasındaki nedensel ilişki ancak fiziksel dünyada gerçekleşebilir; ruh, bilinç, zihin fenomenleri doğanın maddi sürecine müdahale etmeyen ancak bu maddi nedensel sürecin sürekli olmayan sonuçları olarak vardırlar. Buna göre, Santayana'nın töz ve tin nosyonları, maddi nitelikler taşımayan ancak maddi nitelikler ve fiziksel ilişkiler sonucu ortaya çıkan varlıklar olarak tanımlanır (s. 123).

$\mathrm{Bu}$ bağlamda, Santayana felsefesinde öz, töz ve tin epifenomenal varlıklar olarak düşünülmektedir. Benzer şekilde, T. M. Munson (1962) da Santayana düşüncesinde özün maddi karakterini "özler materyalizm bahçesinde açan maddi olmayan çiçeklerdir" (s. 22) şeklinde ifade eder. Bunun yanı sıra, Santayana insanı "epifenomenal ruhun eşlik ettiği maddi bir akıl" olarak tanımlar. Felsefesinde geleneksel idealizmin temel nosyonlarını maddi ve doğal varlıklar olarak sunan Santayana, epifenomenal materyalizmi konusunda israrcıdır ve metafizik varsayım ve kabullerden kaçındığını belirtir. Doğrunun kaynağının her durumda doğa olduğuna inanır ve idealist nosyonları doğa içinde ve doğa yoluyla açıklamaya çalışır. Bu açıdan baktığımızda, Santayana'nın epifenomenal varlık kabulünü ve öz, töz, tin gibi varlıkların maddi doğa ile ilişkisini açıklamak ve natüralizmin temel kabulleri ile bağdaştırmak zordur. Öz, töz ve tinin maddeye indirgenemeyen ancak doğal kabul edilen bu tanımı, Santayana'nın metafiziğinde bu türden düşünsel ya da idealist varlık kabulünden vazgeçemediğini hem de bu varlıklara doğa ile özdeş bir yer arayışında olduğunu göstermektedir.

\section{Santayana'nın Epifenomenal Natüralizmi}

Santayana için bütün gerçeklik doğaldır. "Doğa var olan tüm şeyleri ve insan yaşamının tüm süreçlerini kapsar. Doğal dünya insanın gerçek evidir ve hayvani yaşamdaki bütün inançların spontane ve kaçınılmaz alanıdır" (Stuhr, 1997, s. 132). Natüralist felsefeyi, tüm felsefi sistemlerin eninde sonunda gideceği yer olarak tanımlayan Santayana, bütün felsefi kabullerin maddi dünya temelinde düşünülmesi gerektiğini ve töz, tin, öz gibi nosyonların doğal epifenomenal nosyonlar olarak ele alınması gerektiğini dile getirir. Natüralizmi metafizik karşıtı olarak tanımlayan Santayana, felsefede maddi olmayan şeylerin önceliğinin terkedilmesi gerektiğini iddia eder (Stuhr, 1997, s. 132).

Santayana'nın maddi doğa temelinde sunduğu bu kavramsal çerçevesine ilk itiraz, aynı dönemde yaşamış olan natüralist düşünür John Dewey'den gelmiştir. Dewey ve Santayana birbirlerinin natüralist yaklaşımları üzerine karşılıklı olarak itirazlarda bulunmuşlardır. İki düşünür arasındaki tartışma en temelde Santayana'nın Pragmatik Natüralizmin dolayımsızlık prensibine karşı olması ve deneyimi önceleyen bir varlık alanı tanımlamasına dayanır. Doğa ve deneyimi özdeş kılan Dewey, deneyimin ötesinde ve öncesinde ve aynı zamanda doğayı aşan bir varlık kabulüne karşı çıkar. Bu nedenle, Dewey Santayana'nın natüralist yaklaşımını düalist ve idealist bulurken, Santayana Dewey'nin deneyim 
metafiziği olarak adlandırılan felsefesinin metafizik varsayımlar içerdiğini söyler. Santayana epifenomenal materyalizmine dayanan natüralist yaklaşımını "maddi olaylar döngüsü" (Santayana, 1925, s. 678) olarak tanımlar ve maddi dünyada ruh (tin) maddenin bir ürünüdür. Santayana, Dewey gibi natüralist düşünürlerden farklı olarak deneyim yerine töz ve tini, akıl yerine de hayvan inancını koyar. Kendi felsefesindeki deneyim metafiziği yerine tin ve tözü koyan Santayana'nın kendisinin de alternatif bir metafiziğe düştügünü söyleyen Dewey (Stuhr, 1997, s. 137), Santayana'nın “doğal şeyler içinde hayvan inancı" (Shook, 2003, s. 4) kabulünün doğanın dolayımsız deneyimi kabulünden bir farkı olmadığını iddia eder.

Çağdaş natüralist yaklaşım öncelikli olarak neyi savunduğunu değil neye karşı olduğunu tanımlar ve temel prensip olarak belirler. Buna göre, en temelde doğaüstü ya da aşkın bir varlık alanı, Tanrı, ruh ya da herhangi bir Tanrısallık bu dünyaya dair bir açıklama ya da anlam veremez. Natüralizm anlamını tam da karşı olduğu terimden Doğaüstücülükten (Supernaturalism) alır ve kendini bunun üzerine inşa eder (Stone, 2012, s.481). Bu natüralist kavramsallaştırmaya göre, Santayana'nın epifenomenal nosyonlarının doğal ve maddi oluşu açıklanabilir değildir. Çağdaş natüralist yaklaşım, Santayana'nın natüralist yaklaşımı ile sadece üç temel prensipte uzlaşır: birincisi bilginin deneyim sonucu ortaya çıktığın kabul eden deneyci prensip, ikincisi insan zihninden bağımsız bir gerçekliğin var olduğunu kabul eden realist prensip, ve üçüncüsü insanı doğada yaşayan bir organizma olarak kabul eden biyolojik prensip (Shook, 2003, s.1). Bu açıdan baktığımızda, Santayana natüralizmin en genel prensipleri ile uzlaşsa da, çağdaş yaklaşımın materyalist kabulleri açısından bu çizgiden ayrılmaktadır. Çağdaş natüralist yaklaşımın modern felsefenin mirası olan sübjektivist ve düalist kabullerden kaçınmaya çalışan bakış açısı, organizma olarak özneyi maddi doğa içinde ve doğa ile bütünleşmiş bedenli bir varlık olarak merkeze koyar. Bu bağlamda, böyle bir öznenin doğa ile ilişkisinin dolayımsız bir deneyime dayanması, hem özne ve doğa arasındaki ikiliğin hem de zihin ve beden arasındaki ikiliğin ortadan kalkması açısından önemlidir. Daha önce değinildiği gibi, Santayana da kendi natüralist yaklaşımın geleneksel felsefenin sübjektivist ve düalist bakış açısından kurtulmak bakımından en doğru yol olduğunu iddia eder. Ancak Dewey’nin iddia ettiği gibi, çağdaş natüralist tartışmalarda, Santayana'nın natüralizmi beden ve epifenomenal zihin arasında yaptığı ayrımdan dolayı ontolojik düalizm eleştirisi ile karşı karşıya kalır.

Düalizm eleştirilerinin temelinde Santayana'nın tinin ruhla özdeșliğini, doğallığını ve bedenle ilișkisini belirsiz bir şekilde sunması yatmaktadır. C. G. Conway (2007) Santayana felsefesinde tine dair öne çıkan tanımları analiz ederek bu belirsizliğe dikkat çeker. Buna göre, tin ruhun (psyche) eylemidir, maddi değildir ve bu nedenle bilimin konusu değildir. Ancak tin doğaldır ve doğa ile ilişkilidir. Tin beden değildir ama beden temellidir, yani maddi olana bağlıdır, doğaüstü değildir ve doğal organizmanın içindedir (s. 172). Conway bu belirsizliği tinin aşkınsal (transcendental) bir varlık olduğu şeklinde yorumlar ve şöyle söyler: "Görüyoruz ki, Santayana için tin, doğal, doğal bir ruh içinde ortaya çıkan, ancak maddi olmayan ve aşkınsal bir rütbeye nail olan bir varlık. Peki doğal dünyayı nasıl etkileyebiliyor? Santayana asla doğrudan bir şey söylemiyor" (s. 173).

Santayana'nın maddi olmayan-doğal düşünsel nosyonları kabul etmesi, düşünsel ya da imgelem alanını doğallaştırma çabası ve daha önce söz edildiği gibi, idealizm ile natüralizmi birleștirme çabası olarak görülür. Santayana'y1 "doğal idealist” olarak adlandıran ve felsefesini İdealist Natüralizm olarak tanımlayan düşünürler, bu doğallaştırma çabasını insanın tine ait olan imgelem dünyasının doğa ile karşılaşmasını açıklamak, insanın düşünsel ve ideal üretimlerinin doğal yanını göstermek ve İdealizmin doğal koşullarının ve sınırlarının farkında olmak olarak tanımlarlar (Randall, 1954, s. 50). Ancak natüralizm ile idealizmi birleştirme çabası, daha önce sözüne edildiği gibi, çağdaş natüralizmin materyalist ve bilimci yanı ile karşı karşıya gelmektedir. Kuşkusuz, idealist natüralizm olanaklıdır ve Santayana'nın epifenomenal metafizik yaklaşımı bir tür natüralizm olarak kabul edilmektedir. Ancak, düşünürün natüralizminin bu denli tartışma konusu olması, düşünürün kendisini idealist natüralist bir pozisyondan çok materyalist natüralist bir pozisyonda tanımlaması ve düşünsel nosyonlarının maddi olduğu konusunda ve kendi natüralizminin gerçek natüralizm olması konusundaki ısrarıdır.

Bunun yanı sıra, çağdaş tartışmalarda, Santayana'nın düalizminin kaçınılmaz olarak özne-nesne, doğabilinç, madde-ruh ayrımlarını getireceği iddiası söz konusudur. Santayana'nın aktif maddi dünyaya bu aktif maddi dünyayı birleştiren, bağlayan ve anlam veren bir epifenomenal ön plan koyarak, yani maddi dünyayı önceleyen bir epifenomenal varlık alanı koyarak, bir ikilik yarattı̆gı eleştirisi önemlidir (Stuhr, 1997, s. 140). Deneyimi önceleyen bir epifenomenal varlık alanı, natüralizmin doğa ile özdeşleşen deneyim kavramsallaştırması ile çelişirken, öznenin bu varlık alanına dair kavrayış süreci, 
özneyi doğanın içinde doğal bir organizma olmaktan çok doğanın karşısında rasyonel bir varlığa dönüştürmektedir.

Santayana'nın epifenomenal zihin ve beden arasında yaptığı bu ayrıma karşı ontolojik düalizm eleştirisinin yanı sıra, çağdaş natüralist yaklaşım töz ve form ya da töz ve öz arasındaki ayrıma da karşı çıkar. Çağdaş yaklaşım, doğanın tüm öğelerinin bilinebilir ve maddi formda olmasını öngörür ve Santayana'nın natüralizminin sunduğu madde ile formsuz ve bilinemez olan tin ayrımına karşı çıkar. Çağdaş yaklaşım, tözü özün ve maddenin biraradalığı olarak sunan Santayana'nın madde ve özler dünyası arasında yaptığı ayrımı ve her iki dünyayı da doğanın ve insanın tüm eylemlerinin arka planı olarak tanımladığı yaklaşımını "maddeye tapma" (idolatry of matter) şeklinde tanımlayarak eleştirir (Stuhr, 2000, s. 385).

$\mathrm{Bu}$ eleştirilere karşın, Santayana'nın felsefesini Natüralizmin indirgemeci yaklaşımını ve özellikle ahlaki ve zihinsel süreçleri indirgeme problemini aşma çabası olarak gören ve savunan düşünürler vardır. A. Kerr-Lawson (1989), Santayana'nın natüralizmini sunduğu dört varlık alanı ya da dünya ile (özler dünyası, madde dünyası, tin dünyası, doğruluk dünyası) samimi bir ontolojik yöntem ve kaba ancak indirgemeci olmayan bir natüralizm olarak tanımlar. Kerr-Lawson için Santayana natüralist ve materyalist bir düşünürdür. $\mathrm{Bu}$ bağlamda, Santayana çağdaş natüralizmin ontolojik öncelikleri reddeden ve maddi dünyayı tek öncelik olarak kabul eden yaklaşımını ontolojik bir problem olarak görür. Santayana'nın materyalizmi ise maddenin nedensel önceliğini bir gereklilik olarak sunar ancak epifenomenalist bakış açısıyla bu önceliği fiziksel indirgemecilikten kurtarmaya çalışır. Bu bağlamda Kerr-Lawson'a göre, Santayana'nın natüralizmi bilimsel indirgemeci tavır karşısında etik, estetik, dil ve zihin alanlarını indirgemeci olmayan bir ontoloji ile sunmaktadır. Bunun ötesinde Kerr-Lawson'a göre, Santayana çağdaş natüralizmin, özellikle zihin felsefesi alanında, bilimin konusu olmak bakımından deneyimin konusunu fiziksel maddi dünya ile sınırlayarak, bilinci deneyimin dışına ittiğini düşünmektedir. Santayana için özler ve tinin varlı̆̆ı deneyimde bilincin ontolojik olarak açıklanabilmesi ve açıklığa kavuşturulabilmesi için gereklidir. Bu nedenle, Santayana'nın epifenomenal tin kavramsallaştırması, zihin felsefesinin ontolojik problemlerinin aşılabilmesi açısından gereklidir (Kerr-Lawson, 1986, s. 419).

Genel olarak baktığımızda, Santayana'nın natüralist gelenekte gördügü temel problem, natüralizmin bilimci ya da bilimsel açıklama temelli bakış açısıdır. Santayana bu problemi aşabilmek için, doğal ancak maddi ve fiziksel olan nesneler dünyasına indirgenemeyen bir ontoloji sunmaktadır. Bu ontoloji, doğal dünyanın kavranışında deneyimi önceleyen verili epifenomenal varlık kabulü sunar ve Santayana için varlıkta indirgenemez ve bilimsel olarak konu edilemez bir alan yaratır. Buna karşın, çağdaş yaklaşımın Santayana'nın natüralizminde gördüğü problem ise Santayana'nın temel deneyci ve materyalist kabulleri reddetmesidir. Santayana'nın deneyimin dolayımsız kavrayışını reddetmesi ve deneyimi önceleyen bir arka plan olarak öz ve töz kabulü öncelikli eleştiri konusudur. İkinci olarak, Santayana'nın epifenomenal nosyonları, maddi dünya ile bir nedensel ilişki içinde açıklanamayan, doğal dünyayı nasıl etkiledikleri bilinemeyen ve düşünsel varlıklara tekabül ettiği için idealizm eleştirisi ortaya çıkmaktadır. Ve son olarak, Santayana'nın maddi dünya ile özler dünyası ve genel olarak epifenomenal varlıkların ontolojik statüsü konusunda yapmış olduğu ayrım düalizm eleştirisi ile karşı karşıya kalmaktadır.

\section{SONUÇ}

Sonuç olarak, Santayana'nın kendi natüralizmini gerçek natüralizm olarak tanımladı̆̆ı ontolojisi, geleneksel natüralizm açısından hem ontolojik hem de epistemolojik problemlere neden olmakta ve eleştirilmektedir. Santayana epifenomenal nosyonlar içeren natüralizmi ile doğal ve maddi olduğunu varsaydı ̆̆ indirgemecilikten ve kaba materyalizmden kaçınmak adına maddi olana indirgenemez ancak maddi temelli bir gerçeklik varsayımı, geleneksel natüralizmin düalizm karşıtlığı ile bağdaşmaz görünmektedir. Hem epifenomenal varlıklar varsayımı hem de organizmanın deneyimi ile doğa arasına koyduğu bu maddi olamayan gerçeklik alanı insanın doğa ile ilişkisine sınır çizmektedir. Her ne kadar kendisi "gerçek naturalizm" olarak adlandırsa da, Dewey ve çağdaş yorumcuların Santayana'nın natüralizminin metafizik varsayımlar içerdiği şeklindeki eleştirisi, deneyimi önceleyen bilinemez töz ve öz kabulünden dolayı haklı görünmektedir. Bunun ötesinde, insanın doğa ile ilişkisinin dolayımsızlığı, ya da öznenin nesneyi dolayımsız olarak kavrayışı geleneksel natüralist bakış açısında 
önemli yer tutan bir kabulken ve insanın deneyiminin doğa ile iç içe geçmişliğini temsil ederken, Santayana'nın dolayımsız kavrayışa karşı çıkışı önemli bir çelişkidir. Bilme sürecinde ve insanın doğadaki tüm eylemlerinde zorunlu bir arka plan olarak var sayılan epifenomenal nosyonlar, doğanın ötesinde ve doğaüstü kabulleri içermekte ve Santayana'nın natüralizmini bir idealist natüralizme dönüştürmektedir. Özlerin verili önceliği ve algının özlerin kavranışına bağlı olması insanın doğa ile ilişkisinde bir duvar gibi yorumlanabilir.

Kuşkusuz, Santayana'nın felsefesini epifenomenal nosyonlar üzerinden bir idealist natüralizm olarak okumak olanaklıdır. Düşünür insanın anlam dünyasının düşünsel kavramlarını doğallaştırmaya çalışarak idealizm ve natüralizm arasında bir birliktelik kurmaya çalışmaktadır. İdealist varlık kabulünün farklı biçimlerde doğaya özdeş ya da doğal olarak sunulması, epistemolojik ve ontolojik açıdan olanaklı olduğu gibi, felsefe tarihi boyunca farklı düşünürlerin sunduğu bir yaklaşımdır. Ancak Santayana'nın amacı, bu doğallaştırmayı idealizm temelinde değil de, materyalizm temelinde epifenomenal bir natüralizm olarak sunmaktır. Bu çerçevede natüralizmin indirgemeci tutumunu aşmak isteyen düşünür, natüralizmi kaba bir materyalizmden kurtarmaya çalışırken, idealizmden kurtulamamış görünmektedir. Aynı zamanda, epifenomenal varlık kabulünün hem belirsiz bir nedensellikle sunulan maddi bir temele sahip olduğu iddiası hem de ayrı bir gerçeklik alanı ya da dünya olarak sunulması, idealizmin temelindeki düalizm probleminden kurtulamamış görünmektedir. Bu nedenle, Santayana'nın epifenomenal natüralizmi kendisinin iddia ettiği gibi gerçek bir natüralizm olmak bakımından ve çağdaş natüralizme karşı bir alternatif olmak bakımından kabul görmemiş ve düşünürün iddiaları eleştiri ve tartışma konusu olmuştur.

\section{KAYNAKLAR}

Cory, D. (1950). Some notes on the deliberate philosophy of Santayana, The Journal of Philosophy, 47:5.

Conway, C. G. (2007). Defining spirit: an encounter between naturalist and trans-Naturalist, Theology and Science, 5:2.

Dewey, J. (1927). Half-hearted naturalism, The Journal of Philosophy, 24:3.

Kerr-Lawson, A. (1986). Santayana's epiphenomenalism, Indiana University Press, 22:4.

Kerr-Lawson, A. (1989). Santayana's non-reductive naturalism, Indiana University Press, 25:3.

Munson, T. M. (1962). The Essential Wisdom of George Santayana, New York: Columbia University Press.

Randall, J. H. (1954). George Santayana - Naturalizing the imagination, The Journal of Philosophy, 51: 2 .

Santayana, G. (1923). Scepticism and Animal Faith; Introduction to a System of Philosophy, New York: Dover Publications.

Santayana, G. (1925). Dewey’s naturalistic metaphysics, The Journal of Philosophy, 22:25.

Shook, J. R. (2003). The possibility of an empiricist naturalism: Dewey and Santayana, Overheard in Seville: Bulletin of the Santayana Society, 21.

Stone, J. A. (2012). Spirituality for naturalists, Zygon, 47:3.

Stuhr, J. J. (1997). Genealogical Pragmatism; Philosophy, Experience and Community, Albany: State University of New York Press. 
Stuhr, J. J. (2000). Pragmatism and Classical American Philosophy; Essential Readings and Interpretive Essays, New York: Oxford University Press. 